\title{
AP3 links endosomal TLRs and antigen presentation
}

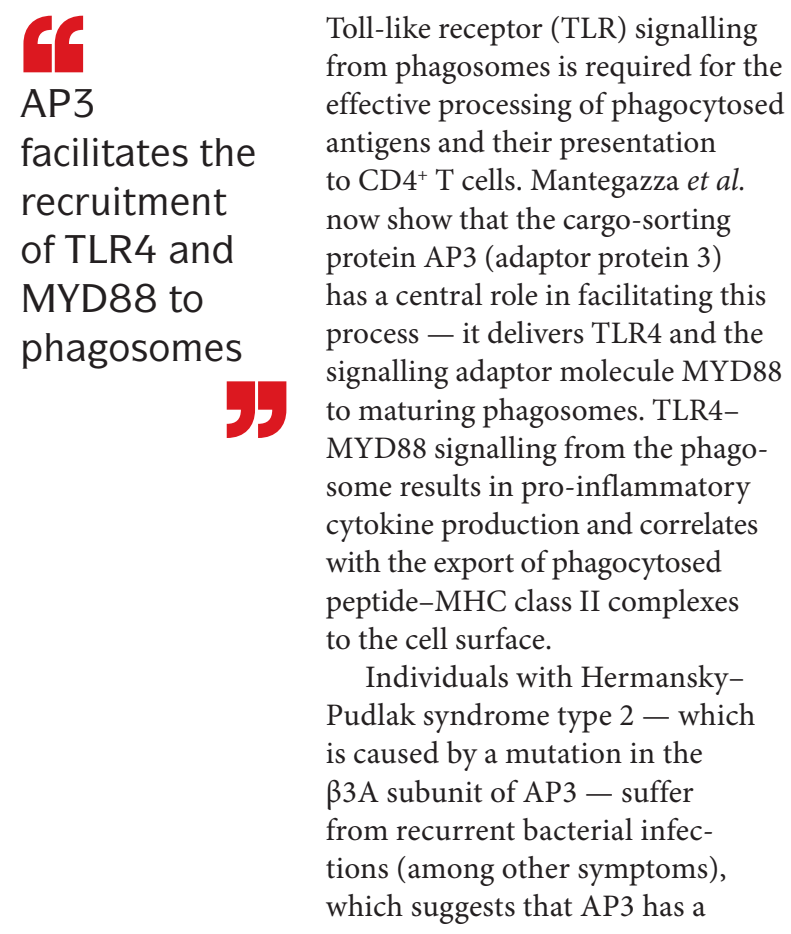

role in antibacterial responses.

Here, the authors show that

AP3-deficient dendritic cells (DCs)

fail to efficiently activate antigenspecific $\mathrm{CD}^{+} \mathrm{T}$ cells and to induce interferon- $\gamma($ IFN $\gamma)$ production by these cells following antigen uptake by phagocytosis, but not after endocytic antigen uptake. Accordingly, AP3-deficient mice had a defective $\mathrm{T}$ helper $1\left(\mathrm{~T}_{\mathrm{H}} 1\right)$ cell response following Listeria monocytogenes infection.

This defect in $\mathrm{T}$ cell activation was not due to impaired antigen phagocytosis but reflected reduced surface expression of peptide-MHC class II complexes on AP3-deficient DCs compared with wild-type DCs. The degradation and MHC loading of phagocytosed antigens were unaffected, but peptide-MHC class II complexes were shown to be retained within punctate structures in AP3-deficient DCs. This suggests

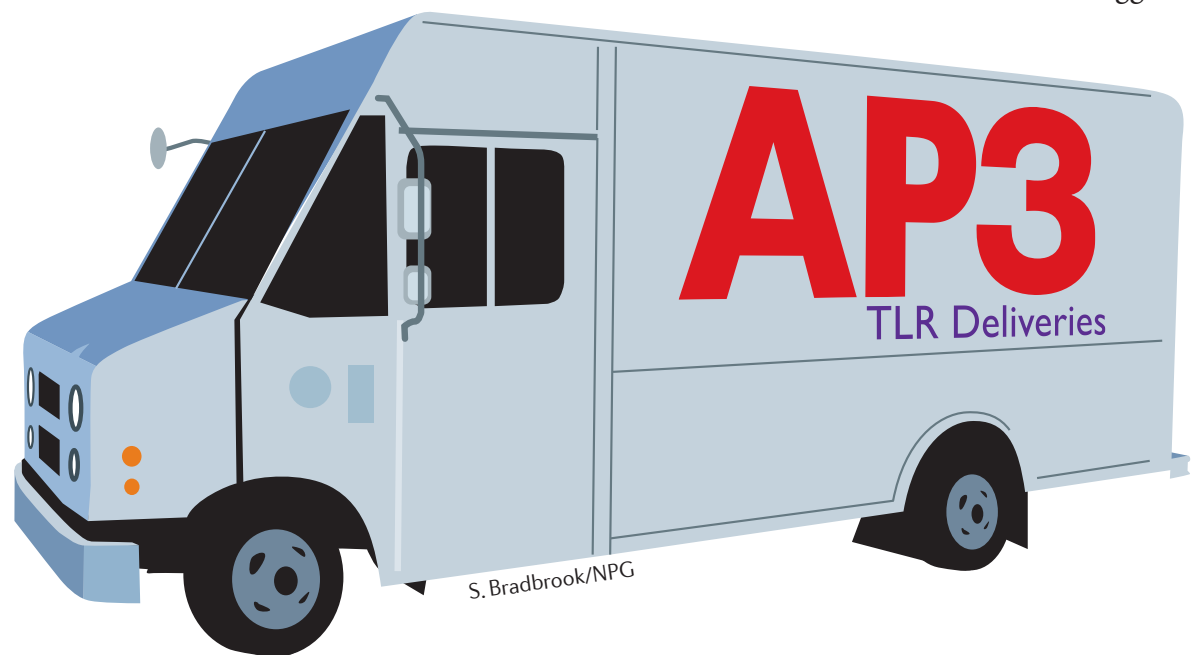

that AP3 is required for the proper delivery of MHC complexes containing phagocytosed antigens to the cell surface.

However, because AP3 is dispensable for the MHC class IImediated presentation of endocytosed antigens, it probably affects the presentation of phagocytosed antigens through an indirect mechanism. Compared with phagosomes from wild-type DCs, phagosomes from AP3-deficient mice had reduced recruitment of TLR4 and MYD88, which are required for pro-inflammatory signalling, but normal recruitment of the TLR4 adaptor molecule TRAM, which is required for type I IFN production. Furthermore, the levels of mRNAs encoding pro-inflammatory cytokines, but not of those encoding type I IFNs, were reduced in AP3-deficient DCs stimulated with the TLR4 ligand lipopolysaccharide in a particulate form (which is phagocytosed).

So, this study suggests that AP3 facilitates the recruitment of TLR4 and MYD88 to phagosomes and raises the possibility that the subsequent phagosome-intrinsic signals are required for effective $\mathrm{MHC}$ class II-mediated presentation of phagocytosed antigens.

Olive Leavy

ORIGINAL RESEARCH PAPER Mantegazza, A. R. et al. Adaptor protein-3 in dendritic cells facilitates phagosomal Toll-like receptor signaling and antigen presentation to $\mathrm{CD} 4^{+} \mathrm{T}$ cells. Immunity 3 May 2012 (doi:10.1016/j.immuni.2012.02.018) 